\title{
Endoscopic transpapillary gallbladder drainage using the balloon occlusion method to advance the guidewire into the cystic duct
}

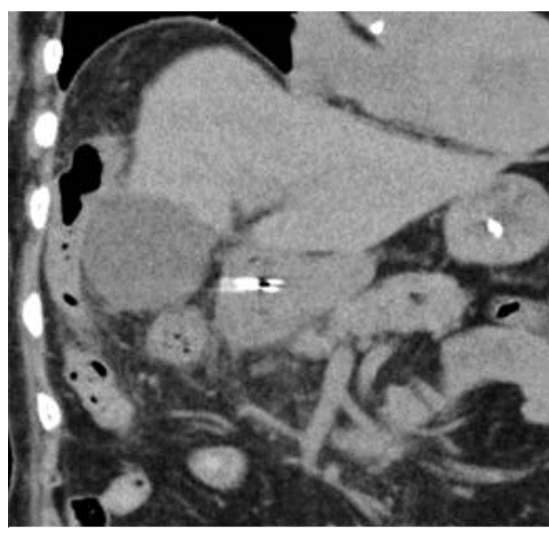

- Fig. 1 Computed tomography showing acute cholecystitis and Chilaiditi syndrome.

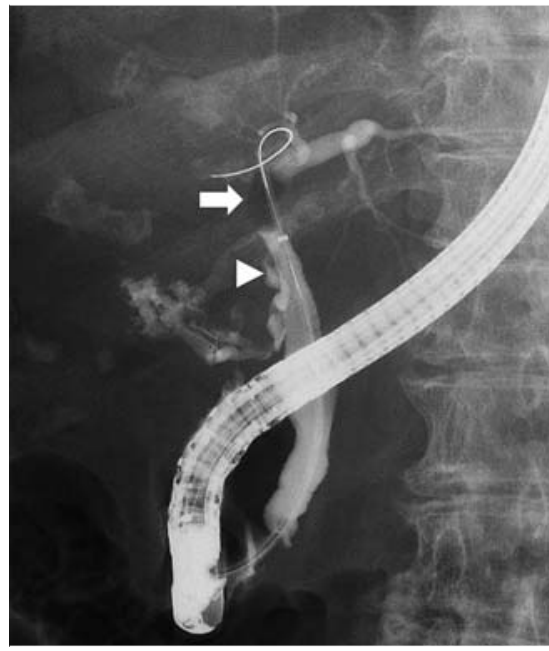

- Fig. 2 Occlusion balloon cholangiography showing the cystic duct with caudal distribution. Arrow: occlusion balloon; arrowhead: cystic duct with caudal distribution.

Endoscopic transpapillary gallbladder drainage (ETGBD) is effective for patients in whom cholecystectomy or percutaneous transhepatic gallbladder drainage (PTGBD) is contraindicated [1, 2]. However, in some patients, the guidewire cannot be advanced into the cystic duct because of the caudal distribution of the cystic duct. Herein, we
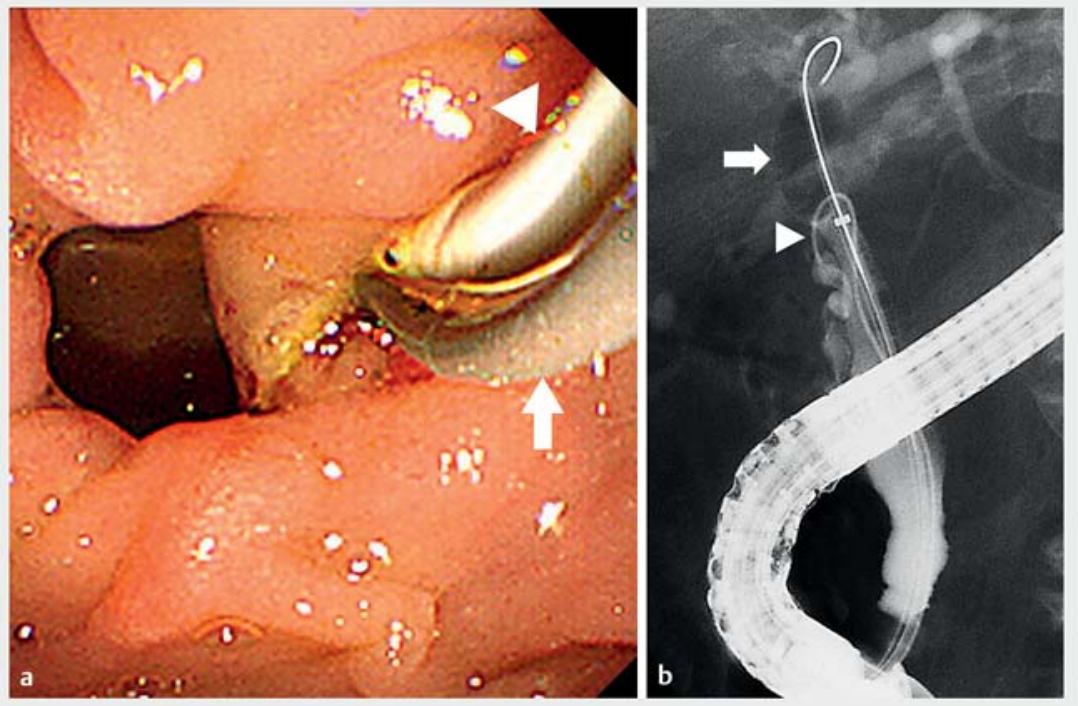

- Fig. 3 A hydrophilic guidewire was inserted into the bile duct using the two-devices-inone-channel method. Then, the guidewire was inverted in the bile duct using the balloon occlusion method and successfully advanced into the cystic duct. a Endoscopic view, b fluoroscopic view. Arrow: occlusion balloon; arrowhead: guidewire.

present a case in which use of the balloon occlusion method enabled guidewire insertion into a cystic duct with caudal distribution, thus allowing ETGBD to be successfully performed.

An 82-year-old woman with right upper quadrant pain and high fever was admitted to our hospital and diagnosed with acute cholecystitis and Chilaiditi syndrome based on CT findings ( $\mathbf{F i g} . \mathbf{1}$ ). In view of the high surgical risk and contraindication of PTGBD because of the Chilaiditi syndrome, the patient underwent ETGBD. After bile duct cannulation, the cystic duct could not be visualized by cholangiography via the cannula, and guidewire insertion into the cystic duct was impossible. Hence, we inflated an occlusion balloon below the bifurcation of the hilar bile duct and injected a contrast agent via the proximal port of the balloon catheter; this allowed detection of the cystic duct ( Fig.2). However, the guidewire could not be advanced into the cystic duct because of the caudal distribution of the duct. Therefore, we inflated the occlusion balloon right above the origin of the cystic duct takeoff. Using a two-devices-in-one-channel method [3], we inserted a hydrophilic guidewire (Radifocus; Terumo Co. Ltd., Tokyo, Japan) into the bile duct ( $\triangleright$ Fig. 3a). Then, the guidewire was inverted in the bile duct by the inflated balloon, thereby successfully advancing into the cystic duct ( $\triangleright$ Fig.3b). After the hydrophilic guidewire was inserted into the gallbladder ( $>$ Fig.4a), it was changed to a stiff type. Finally, we placed a spiralshaped plastic stent [4], positioning the tip at the gallbladder fundus ( $>$ Fig. $\mathbf{4 b}$ ). This case shows that the balloon occlusion method can be useful to successfully perform ETGBD, particularly in patients with caudal distribution of the cystic duct ( $\triangleright$ Video 1 ).

Endoscopy_UCTN_Code_TTT_1AR_2AK 

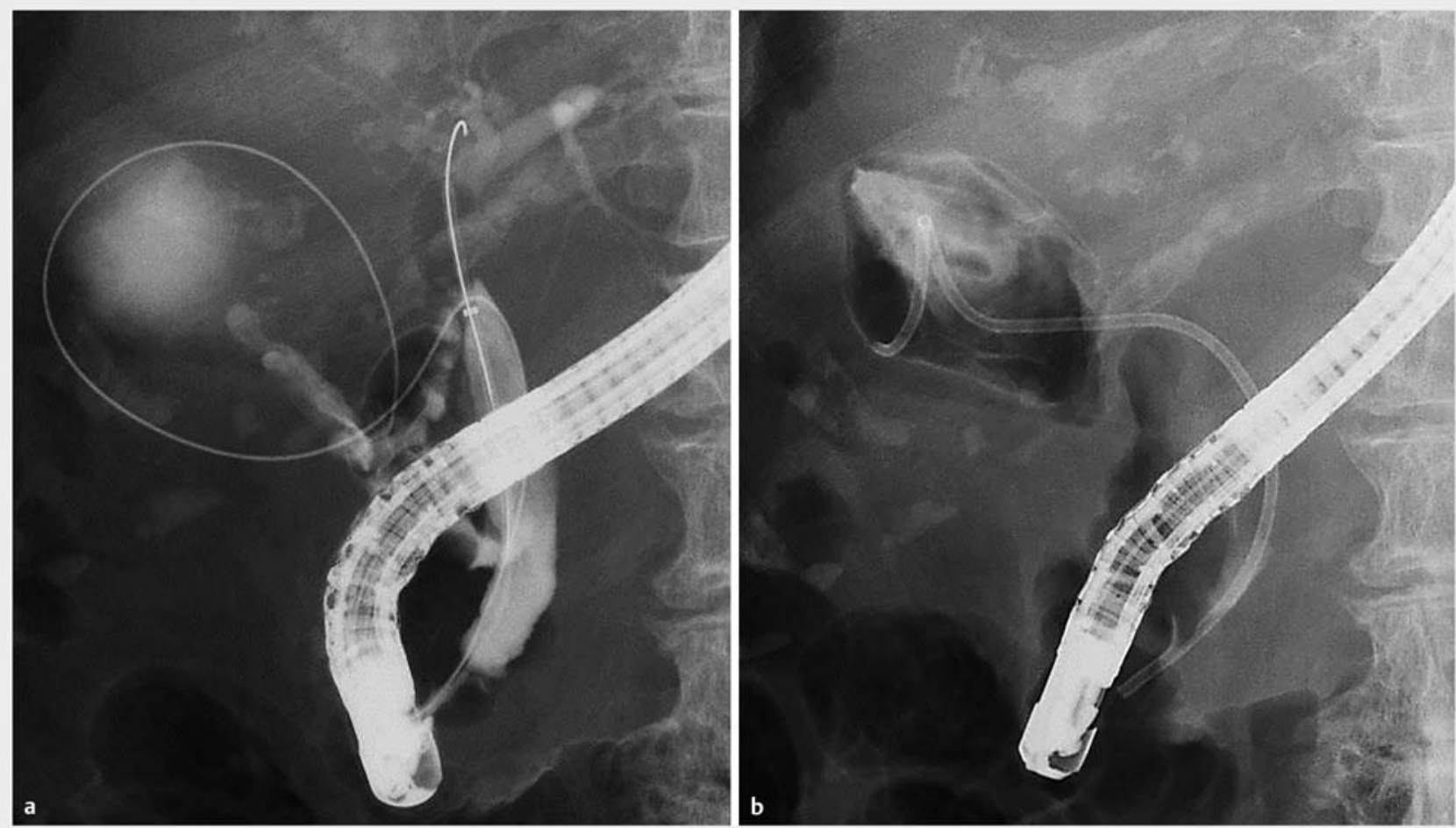

Fig. 4a The guidewire was inserted into the gallbladder through the cystic duct. b The spiral-shaped stent was placed in the gallbladder.

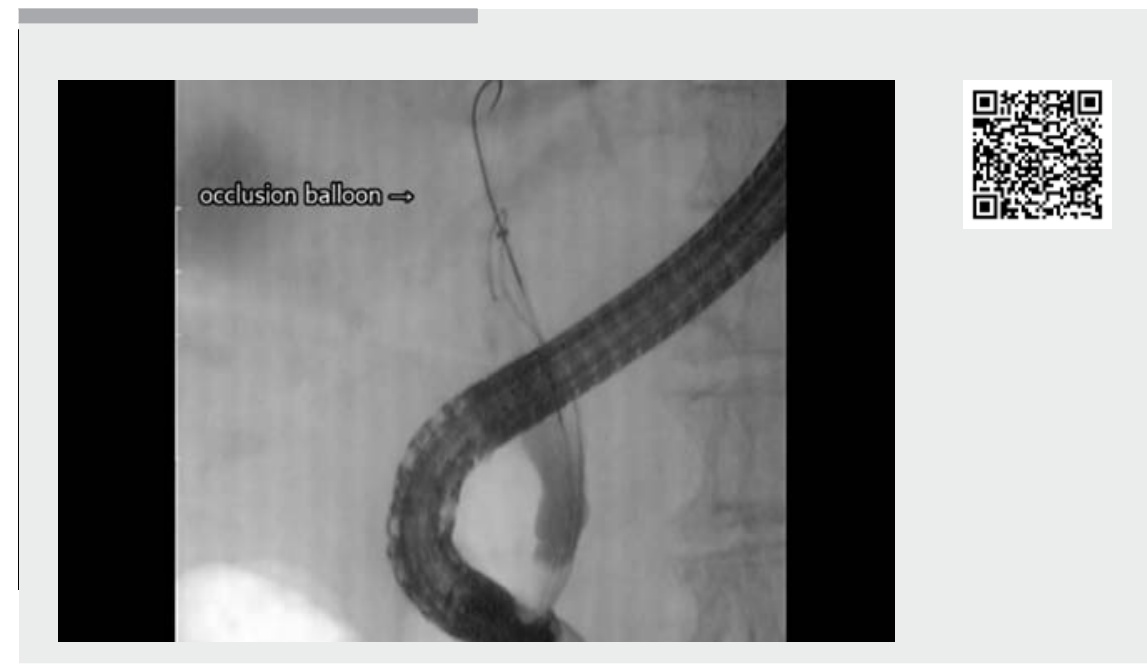

1 Department of Gastroenterology and Hepatology, St. Marianna University School of Medicine, Kawasaki, Japan

2 Department of Gastroenterogical and General Surgery, St. Marianna University School of Medicine, Kawasaki, Japan

\section{Corresponding author}

\section{Kazunari Nakahara, PhD}

Department of Gastroenterology and Hepatology, St. Marianna University School of Medicine, 2-16-1, Sugao, Miyamae-ku, Kawasaki, 216-8511 Japan Fax: +81-44-9765805 nakahara@marianna-u.ac.jp

$\checkmark$ Video 1 Balloon occlusion method for advancing a guidewire into a cystic duct with caudal distribution in endoscopic transpapillary gallbladder drainage.

\section{References}

[1] Itoi T, Sofuni A, Itokawa F et al. Endoscopic transpapillary gallbladder drainage in patients with acute cholecystitis in whom percutaneous transhepatic approach is contraindicated or anatomically impossible (with video). Gastrointest Endosc 2008; 68: 455460 
[2] Mori Y, Itoi T, Baron TH et al. Tokyo Guidelines 2018: management strategies for gallbladder drainage in patients with acute cholecystitis (with videos). J Hepatobiliary Pancreat Sci 2018; 25: 87-95

[3] Fujita N, Noda Y, Kobayashi G et al. ERCP for intradiverticular papilla: two-devices-inone-channel method. Endoscopic retrograde cholangiopancreatography. Gastrointest Endosc 1998; 48: 517-520

[4] Nakahara K, Michikawa Y, Morita R et al. Endoscopic transpapillary gallbladder stenting using a newly designed plastic stent for acute cholecystitis. Endosc Int Open 2019; 7: E1105-E1114
Bibliography

DOI https://doi.org/10.1055/a-1125-5826

Published online: 18.3.2020

Endoscopy 2020; 52: E339-E341

(c) Georg Thieme Verlag KG

Stuttgart · New York

ISSN 0013-726X

\section{ENDOSCOPY E-VIDEOS}

https://eref.thieme.de/e-videos

口回 Endoscopy E-Videos is a free 登视 回: on interesting cases and new techniques in gastroenterological endoscopy. All papers include a high quality video and all contributions are freely accessible online.

This section has its own submission website at

https://mc.manuscriptcentral.com/e-videos 